\title{
Towards understanding the structure of the capsid of Banana Bunchy Top Virus
}

\author{
Sundaram Sairama, Ramasamy Selvarajana, Savithri S Handanahallib, Sangita Venkataraman ${ }^{*}$ \\ a ICAR National Research Centre for Banana, Thayanur Post, Tiruchirapalli 620102, India \\ b Indian Institute of Science, Bangalore 560012, India \\ c Department of Biotechnology, Acharya Nagarjuna University, Nagarjuna Nagar, Guntur 522510, India \\ * Correspondence: sangita.venkataraman@gmail.com (S.V.)
}

\begin{abstract}
Banana is the major staple food crop for approximately 400 million people. Bunchy Top disease of Banana is one of the most devastating diseases caused by Banana Bunchy Top Virus (BBTV) that results in a significant loss of yield, stunting and bunchy appearance of leaves. While many isolates of BBTV from various regions of India have been characterized by different groups, no structural study exists for this important virus. To pursue structural studies, the pET28a clone of coat protein (CP) gene from BBTV isolate of Hill Banana grown in lower Pulney Hills (Virupakshi) of Tamilnadu was expressed in BL21 (DE3) pLysS. Purification of the CP was done using Ni-NTA affinity chromatography. In vitro capsid assembly studied using sucrose density gradient centrifugation suggested that the $\mathrm{CP}$ did not assemble as virus like particle (VLPs) but remained as smaller oligomers. Studies using dynamic light scattering (DLS) indicates that the purified protein is poly-dispersed represented majorly as pentamers. Studies using both homology modelling and $a b$ initio structure determination gave useful insights into the probable fold of the CP suggesting it is a $\beta$-sandwich fold similar to that seen in majority of plant viruses. In silico capsid reconstruction aided understanding of the quaternary organization of subunits in the capsid and molecular interactions present between the subunits. The location of aphid binding EAG motif was identified on the surface loops close to the pentameric axis indicating their role in vector mediated transmission.
\end{abstract}

\section{Introduction}

X-ray diffraction studies on single crystals of viruses enable visualization of the structures of intact virus particles at near-atomic resolution. These studies provide detailed information regarding the $\mathrm{CP}$ folding, capsid architecture, molecular interactions between protein subunits, and plausible sites of receptor recognition (Prasad \& Schmid, 2012; Venkataraman et al., 2008). Such learning is pivotal in designing strategies for combating infections due to viruses in plants, animals and humans. Banana and plantains are grown in about 120 countries in mixed cropping systems by small holders and occasionally in monoculture (INIBAP, 2002). India is 
the largest producer of Banana in the world. Of 1919 million tonnes of banana that was produced globally in 2018, India accounted for 116.1 million tonnes (FAO. 2019. Banana Statistical Compendium 2018. Rome., n.d.). Banana is an important fruit crop of many tropical and subtropical regions of the world including India, Philippines and China. BBT disease of Banana is one of the most devastating diseases caused by BBTV that results in a significant loss of yield, stunting and bunchy appearance of leaves (Figure 1) (Dale, 1987; Qazi, 2016; Vetten, 2008).

BBTV is a member of Nanoviridae and represents the genus Babusvirus (Burns et al., 1995; Malathi \& Renuka Devi, 2019). It belongs to group II viruses under Baltimore classification and is characterized by single stranded DNA (ssDNA) genome. The genome is multipartite consisting of six to eight circular segments that are separately encapsidated inside individual icosahedral shells of $\mathrm{T}=1$ symmetry. The non-enveloped shell is a small round capsid of about 18 to $19 \mathrm{~nm}$ in diameter and is made of viral CP, which is encoded by one of the segments of the genome, DNA-S. The virus is known to infect all members of Musaceae family and is transmitted by aphids ((King et al., 2012; Mandal, 2010; Qazi, 2016; Venkataraman \& Selvarajan, 2019).

Globally, many groups have worked on characterizing BBTV from various countries like Pakistan (Amin et al., 2008), Africa (Kumar et al., 2011), China (Yu et al., 2011), Indonesia (Chiaki et al., 2015; Stainton et al., 2015), India (Banerjee et al., 2014; Selvarajan et al., 2010; Selvarajan \& Balasubramanian, 2013; Vishnoi et al., 2009) and Srilanka (Wickramaarachchi et al., 2016). Since, BBTV is naturally transmitted by aphid vectors, a number of studies have been undertaken to get a deeper understanding of the mechanism of transmission (Hooks et al., 2009; Watanabe et al., 2016). There have been many research articles on the techniques of identification of BBTV in the fields. These include Direct Antigen Coated (DAC) ELISA and Double Antibody Sandwich (DAS) ELISA (Chen \& Hu, 2013; Mansoor et al., 2005). Other sophisticated ways of detection involves tissues disruption from banana plants followed by real-time TaqMan(®) PCR that is highly sensitive and could detect as few as 2.76 copies of BBTV genomic DNA or $1.0 \mathrm{ng}-1.0 \mathrm{mg}$ of infected banana leaves (Chen \& Hu, 2013). Recently, paper-based gene based sensors have been developed for identifying contagious plant viruses in the fields (Wei et al., 2014). Since BBTV has a multipartite genome, different studies have focused on the recombination and reassortment ability of BBTV genome (Stainton et al., 2015). $\mathrm{Fu}$ et al., (2009) have researched on the evolution of BBTV by studying the various recombination events (Fu et al., 2009). A recent study involving identification and in silico characterization of defective molecules associated with isolates of BBTV has suggested the 
involvement of defective DNA-R molecules (Stainton et al., 2015). An interesting study by Zhuang et al. has revealed the antagonistic effect of BBTV multifunctional protein B4 against Fusarium oxysporium (Zhuang et al., 2016). In a different study, Selvarajan and Balasubramaniam (Selvarajan \& Balasubramanian, 2014) have cloned and sequenced the complete genome comprised of six DNA components of BBTV infecting Hill Banana grown in lower Pulney hills of Tamil Nadu State in India. Transgenic banana plant expressing siRNA to develop resistant varieties were developed by various groups (Elayabalan et al., 2015; Shekhawat et al., 2012). The replication initiation protein of Nanovirids esp of Abaca bunchy top virus (ABTV) and BBTV have been recently reviewed (Venkataraman \& Selvarajan, 2019).

Considering the impact of Banana in our economy and growth, significant research and studies have been undertaken to prevent and treat diseases of bacteria, virus and fungi that affect banana. However, structural studies are lacking for this important class of virus infecting Banana plantation all over the world. Hence, the present study focuses on getting insights into the structure of BBTV CP and capsid by undertaking cloning of the CP in pET28a vector and overexpressing in bacterial system to purify sufficient protein for crystallographic studies. However, due to very low yield of CP protein, crystallization attempts have been unsuccessful so far. Modeling studies and Ab initio structure prediction of $\mathrm{CP}$ followed by in silico reconstruction of entire BBTV capsid provided deeper understanding of assembly, quaternary organization and interactions of BBTV. The results obtained from various studies are discussed in the current paper.

\section{Methodology}

\section{Cloning studies}

The infected leaf samples of BBTV were collected from the farmer's field near National Research Center for Banana and confirmed by direct antigen coating (DAC) ELISA utilizing polyclonal antiserum of BBTV. The total DNA was extracted from the infected leaves through CTAB method (Selvarajan et al., 2008). The 513 bp gene of CP was amplified through PCR using standard CP specific primers (forward 5'-ATG GCTAGGTATCCGAAGAAATCC-3' and reverse 5' TCAAACATGATATGTAATTCTGTTC -3'). The initial denaturation was for $5 \mathrm{~min}$ at $94^{\circ} \mathrm{C}$; followed by 30 s denaturation at the same temperature, annealing for 45 secs at $53^{\circ} \mathrm{C}$, and extension at $72^{\circ} \mathrm{C}$ for 30 cycles. The PCR products were analyzed in agarose gel. The CP gene was purified post PCR and was cloned into pET-28a (+) vector between XhoI and NcoI sites and confirmed by sequencing (AF148945.1:227-739). 


\section{Expression and Purification}

The pET28a plasmid with BBTV CP gene was transformed into BL21 (DE3) pLysS, plated on LB-agar. Single colony was inoculated into LB broth and left $\mathrm{O} / \mathrm{N}$ for growth at $37^{\circ} \mathrm{C} .1 \%$ primary culture was used for inoculating $500 \mathrm{ml}$ of LB broth (Secondary culture). The secondary culture was induced at 0.6 OD with IPTG at a concentration of $1 \mathrm{M}$. Post induction, the culture was kept at $37^{\circ}$ for 3 hrs for protein expression. The expression was studied at various induction temperature, IPTG concentrations and against different bacterial strains such as Rosetta and codonPlus. The cells were harvested by centrifugation for 10 mins at $8000 \mathrm{rpm}$. The pellet was suspended in the Lysis Buffer containing 20mM Tris (pH8) and sonicated using VibraCell ultrasonic processor at 50\% amplitude/ $10 \mathrm{sec}$ pulse/ $20 \mathrm{sec}$ rest/ $20 \mathrm{~min}$ in ice. The soluble and insoluble fractions were separated following cell lysis. For every bacterial strain used, the lysis buffer composition was varied, and the solubility was assessed. Further purification was carried out using affinity chromatography using Ni-NTA resin. Two rounds of washing using buffers with $20 \mathrm{mM}$ and $30 \mathrm{mM}$ Immidazole concentration was carried out prior to elution with $300 \mathrm{mM}$ Immidazole. The elute was subjected to dialysis to remove the imidazole and concentrated to $1 \mathrm{ml}$. The final purified protein was checked on the gel, the concentration was assessed by absorbance at $280 \mathrm{~nm}$. The 260/280 ratio was taken for assessing the presence of nucleic acid.

\section{Protein Characterization}

\section{Density Gradient Centrifugation}

The clear supernatant post cell lysis was transferred into $32 \mathrm{ml}$ ultra-centrifuge tubes and spun at 26,000 rpm for 3 hours at $4^{\circ} \mathrm{C}$ in AH629 rotor. The ultra-pellet was suspended in a small volume of $20 \mathrm{mM}$ Tris buffer ( $\mathrm{pH} 7.5$ ) through end-to-end rotation, layered onto tubes with 10 $-40 \%$ sucrose density gradient and centrifuged at 26,000 rpm for 3 hours. Following the run, $1.5 \mathrm{ml}$ fractions were collected from the bottom of the gradient. The presence of VLPs was assessed by studying the presence of light scattering zone, monitoring the absorbance of the fractions at $280 \mathrm{~nm}$ and SDS-PAGE analysis (He, 2011).

\section{Dynamic Light Scattering (DLS)}

Protein solution, buffer, $100 \% \mathrm{EtOH}$, and MQ H2O were filtered through $0.1 \mu \mathrm{m}$ filters prior to the experiment. The concentration of protein was kept at $\sim 1 \mathrm{mg} / \mathrm{ml}$. DLS experiments were performed using Viscotek 802 DLS in a quartz cuvette (volume, $12 \mu \mathrm{l}$ ) at $22{ }^{\circ} \mathrm{C}$. 


\section{In silico structure predictions}

The amino acid sequence of BBTV CP (Q65386) was retrieved from the SwissProt database (Bairoch, 2000) and used as target for ab initio structure prediction and homology modelling using various servers that are available online or using commercial packages such as Schrodinger (Schrödinger, 2018). Since the protein sequence identity for the BBTV CP with all the available proteins of PDB was very poor $(<20 \%)$, a proper homologous model is unavailable. Ab initio structure prediction was done using iTASSER (Iterative Threading ASSEmbly Refinement) (Yang \& Zhang, 2015), Robetta (Kim et al., 2004; Ovchinnikov et al., 2018) and Quark (Xu \& Zhang, 2012, 2013), while homology modeling was attempted using Schrodinger (Schrödinger Release 2019-4: Prime, Schrödinger, LLC, New York, NY, 2019), SwissModeler (Bienert et al., 2017), RaptorX (Källberg et al., 2012, 2014), Phyre (Kelley et al., 2015; Kelley \& Sternberg, 2009) and MMM (Jeschke, 2018). The models were subjected to quality evaluation using QMean server (Benkert et al., 2009, 2011) and SAVES (Pontius et al., 1996) for assessing structure quality. The best scoring model was considered for further analysis. The disorder was assessed using the PrDOS (Ishida \& Kinoshita, 2007), and the nucleic acid binding was assessed using bindUP server (Paz et al., 2016).

\section{Model Validation}

The finalized model was energy minimized using the protein-preparation wizard of the Schrodinger suite to corrects problems such as missing hydrogen atoms, incomplete side chains and loops, ambiguous protonation states, and flipped residues (Schrödinger, 2018). Following minimization, the model was exported to the SAVES server Version 5.0 (Pontius et al., 1996) and their overall stereochemical quality, including backbone torsional angles was checked through the Ramachandran plot using the program PROCHECK (Laskowski et al., 2012).

\section{VIPERdb analysis}

In silico capsid reconstruction was done using VIPER and the capsid features were analyzed using the VIPERdb server (Carrillo-Tripp et al., 2009; Ho et al., 2018). The inner and outer radii are calculated by the server after deriving the minimum and maximum distance calculated from the origin $(0,0,0)$ going over all the atoms. The number of inter-residue contact between a pair of residues from two (different) subunits was evaluated by VIPERdb using the criteria that the distance between the center of mass of the side chain atoms is within the distance criteria as estimated on the basis of the structures available in PDB (Godzik et al., 1992). 
Subunit association energies were estimated by the server as the product of atomic buried surface areas and the solvation parameters (Eisenberg \& Hill, 1989; Horton \& Lewis, 1992). The program CHARMM was used to calculate the Buried surface areas applying a probe radius of 1.4A (B. R. Brooks et al., 2009; Bernard R. Brooks et al., 1983).

\section{Results and Discussion:}

\section{Cloning and expression results:}

The total DNA was extracted from the BBTV infected leaf sample and CP gene was amplified using the standard primers through PCR (Figure 2a). The CP gene was cloned into pET28a vector between XhoI and NcoI sites following purification of the PCR product (Figure 2b). The clone was also confirmed using sequencing. After standardization of expression, a 21 culture was lysed with solution containing 25mM Tris, 100mM Nacl, 1\% Triton X 100 and $10 \mathrm{mM}$ Immidazole and further purified using affinity chromatography. Figure $3 \mathrm{a}$ and $3 \mathrm{~b}$ show the overexpression of $\mathrm{CP}$ protein and the purified band following affinity chromatography, respectively. A band of $18.9 \mathrm{KDa}$ corresponding to the $\mathrm{CP}$ was observed in $0.8 \%$ SDS PAGE (Figure 3b). The 260/280 ratio of 0.8 indicated the absence of nucleic acid in the preparation. To check if the expressed CP assembled into VLPs, the lysate was subjected to sucrose density gradient centrifugation (Figure 4a). No light scattering zone was observed. The absorbance of the fractions were recorded and the samples were run on a $0.8 \%$ gel. No bands were observed in the gel and the absorbance was insignificant indicating that the expressed BBTV-CP did not assemble into $\mathrm{T}=1$ capsid.

Unlike the native capsid, there was absence of any nucleic acid association indicating that specific interactions with ssDNA was probably mandatory for proper folding of the $\mathrm{CP}$ and eventual capsid assembly (Sangita et al., 2004; Satheshkumar et al., 2004). The DLS results also indicated that the CPs did not form regular capsids but instead were poly-dispersed with a greater population of pentamers over other species (Figure 4b). As the yield of the protein was insufficient for crystallization trials in silico methods were employed for gaining understanding of the nature and structure of the CP.

\section{In silico modeling}

Table 1 shows the results of in silico modeling obtained using both ab initio structure prediction and homology modeling with various servers. While the servers and programs predicted a consistent $\beta$ structure for the overall model with regions of disorder at the amino terminus, there was not much of agreement between the other regions of the protein. While the coverage 
and QMean score was better for the ab initio model predicted by Robetta (Das \& Baker, 2008; Ovchinnikov et al., 2018), they were less encouraging for others. Hence, the model predicted by Robetta was used for further analysis. The Robetta server used c-terminal domain of polymerase basic protein 2 from influenza virus (PDB ID: h5n1) as reference protein for building the model. The same protein was picked by ITASSER, Schrodinger and Phyre as the reference protein for modeling the structure.

The ab initio structure predicted by Robetta was energy minimized using the protein preparation wizard of schrodinger and structure quality analysis was performed using the SAVES server (Pontius et al., 1996). The quality of the model was good with $81.18 \%$ of the residues with averaged $3 \mathrm{D}-1 \mathrm{D}$ score $>=0.2$. The model showed $85.4 \%$ of the residues within the most favored regions (red), $12.6 \%$ residues within the additionally allowed regions (yellow), $0.7 \%$ within the generously allowed regions (beige), and only $1.3 \%$ residues of modeled proteins in the disallowed regions (white) (Figure 5a). Thus, the overall stereochemical properties of the model was reliable and was used for further studies. A very basic amino terminal end that is unstructured for more than 30 residues is a characteristic feature of the CP model. Analysis using Protein Disorder prediction System (PrDOS, (Ishida $\&$ Kinoshita, 2007), Figure 5b) also suggested that the disorder at the amino-terminus (Figure 4b). Analysis of nucleic acid binding using BindUP server (Paz et al., 2016) (Table 2) also strongly indicated the role of the highly basic amino terminal end towards recognition and binding of cognate genome (Figure 6a). A total of 13 basic residues are present amongst the first 30 amino acids at the amino terminus, mostly featuring lysines. The fold seems to be similar to the $\beta$-sandwich fold of the CPs of other plant viruses (Figure $6 b$ ) consisting of two $\beta$ -sheets packed against each other. Sheet 1 is seen to comprise of the three strands A, F and G while sheet 2 comprises of strands B, D. Two short helices are present, $\alpha 1$ between $\beta A$ and $\beta B$ and $\alpha 2$ between $\beta E$ and $\beta F$. Strand $A$ is the shortest comprising of 4 residues while strand $\beta F$ is the longest comprising of 15 residues.

\section{Structure analysis}

To study the capsid assembly, the model coordinates of BBTV CP were transformed into PQR system using VIPERdb (Carrillo-Tripp et al., 2009; Ho et al., 2018) in which the icosahedral 2-fold axes are along the $\mathrm{P}, \mathrm{Q}$ and $\mathrm{R}$ directions. The PDB to VIPER transformation matrix is: $0.3090 .809-0.500$ 


\subsection{0 .3090 .809}

With a translation of $0.0 \quad 0.0 \quad 0.0$.

The resultant coordinates of the model were used to generate the capsid shell using the 60 icosahedral matrices through the VIPERdb server and the structure was subjected to VIPER analysis (Carrillo-Tripp et al., 2009; Ho et al., 2018). The capsid thus obtained was a closely packed $\mathrm{T}=1$ icosahedron with an average particle radius of $97.0 \AA$ that matches with the diameter of the particles seen under EM (Figure 7a). The model capsid also displays a smooth contour similar to that observed for the natural virus. The outer radius of 97.0 and inner radius being $58.0 \AA$ is consistent with the observed particle diameter in EM studies (Harding et al., 1991; Qazi, 2016). The spherical volumes based on the standard formula, 4/3( $\mathrm{Pi}^{*} \operatorname{Radius}^{\wedge} 3$ ) estimated from the average radius was $3,822,995.7 \AA^{3}$. The solvent accessible surface area (SASA) was estimated to be $5,143.7 \AA^{2}$ per subunit of the capsid. The net surface charge was calculated by adding the charges of residues that are surface-exposed (both positive and negative) was estimated to be $+900 \mathrm{e}$ per virion indicating a highly positive surface. The modelled capsid was analyzed for short contacts and association energies. The contact table (Table 2) indicates a total of 40 unique contacts with seven polar contacts, five hydrophobic and two salt bridges at the A1-A2 interface. The association energy between the A1-A2 interface area is $-44 \mathrm{Kcal} / \mathrm{mol}$ with a buried surface area of $2184.1 \AA^{2}$ and solvation energy of $20.2 \mathrm{Kcal} / \mathrm{mol}$. Overall the viral capsid resembles a loosely tethered association of twelve pentamers linked by feeble inter-pentameric contacts. This aspect is in agreement with the fact that in the DLS studies one could see a large proportion of pentameric population. The lack of strong inter-pentameric contacts and association is likely the reason that the particles are not readily observable either in vivo or in vitro conditions. The amino terminal disordered region is seen at the interface lining the pentamers and facing the interior (Figure 6a). It is most likely that nucleic acid mediated interactions play a major role in holding the pentamers together against the otherwise wobbly and basic amino terminal end. Further, BBTV which is primarily transmitted by aphids, lacks the conventional DAG motif in the CP. But instead the EAG motif (residues 118-120) is present and strategically positioned in the highly accessible loop between $\beta \mathrm{F}$ and $\beta \mathrm{G}$ at the pentameric axes in the capsid model (Figure $7 \mathrm{~b}$ ). As previously suggested, EAG could be a potential aphid binding motif and this is conserved in BBTV as well as ABTV. Till date attempts by various international groups to raise monoclonal antibodies against BBTV have been unsuccessful indicating the difficulties in raising antisera for detection of the virus 
(Mandal, 2010; Qazi, 2016). The predicted capsid structure of BBTV presents valuable insights into why they are inherently unstable and how they contribute towards vector transmission,

\section{Conclusion:}

BBTV is an economically important virus infecting banana plantation around the world. An attempt to understand the structural features of this small virus of $18 \mathrm{~nm}$ diameter possessing a $\mathrm{T}=1$ shell comprising of 60 subunits of CPs of $19 \mathrm{KDa}$, the CP gene was cloned into pET28a expression vector and was expressed in E.Coli BL21 DE3 cells. The protein was purified using Ni-NTA ion exchange chromatography. The low yield of the protein hampered crystallographic attempts. Meanwhile, in silico structure determination has been undertaken to predict the structural aspects and derive some idea on possible aphid binding motifs for long term plans to control BBTV infestation.

\section{Acknowledgement:}

SV acknowledges the support of SERB for funding the study (ECR/2016/000242). 


\section{References:}

Amin, I., Qazi, J., Mansoor, S., Ilyas, M., \& Briddon, R. W. (2008). Molecular characterisation of Banana bunchy top virus (BBTV) from Pakistan. Virus Genes. https://doi.org/10.1007/s11262-007-0168-y

Bairoch, A. (2000). The SWISS-PROT protein sequence database and its supplement TrEMBL in 2000. Nucleic Acids Research. https://doi.org/10.1093/nar/28.1.45

Banerjee, A., Roy, S., Behere, G. T., Roy, S. S., Dutta, S. K., \& Ngachan, S. V. (2014). Identification and characterization of a distinct banana bunchy top virus isolate of Pacific-Indian Oceans group from North-East India. Virus Research, 183, 41-49. https://doi.org/10.1016/j.virusres.2014.01.017

Benkert, P., Biasini, M., \& Schwede, T. (2011). Toward the estimation of the absolute quality of individual protein structure models. Bioinformatics. https://doi.org/10.1093/bioinformatics/btq662

Benkert, P., Künzli, M., \& Schwede, T. (2009). QMEAN server for protein model quality estimation. Nucleic Acids Research. https://doi.org/10.1093/nar/gkp322

Bienert, S., Waterhouse, A., De Beer, T. A. P., Tauriello, G., Studer, G., Bordoli, L., \& Schwede, T. (2017). The SWISS-MODEL Repository-new features and functionality. Nucleic Acids Research. https://doi.org/10.1093/nar/gkw1132

Brooks, B. R., Brooks, C. L., Mackerell, A. D., Nilsson, L., Petrella, R. J., Roux, B., Won, Y., Archontis, G., Bartels, C., Boresch, S., Caflisch, A., Caves, L., Cui, Q., Dinner, A. R., Feig, M., Fischer, S., Gao, J., Hodoscek, M., Im, W., ... Karplus, M. (2009). CHARMM: The biomolecular simulation program. Journal of Computational Chemistry. https://doi.org/10.1002/jcc. 21287

Brooks, Bernard R., Bruccoleri, R. E., Olafson, B. D., States, D. J., Swaminathan, S., \& Karplus, M. (1983). CHARMM: A program for macromolecular energy, minimization, and dynamics calculations. Journal of Computational Chemistry. https://doi.org/10.1002/jcc.540040211

Burns, T. M., Harding, R. M., \& Dale, J. L. (1995). The genome organization of banana bunchy top virus: Analysis of six ssDNA components. Journal of General Virology. https://doi.org/10.1099/0022-1317-76-6-1471

Carrillo-Tripp, M., Shepherd, C. M., Borelli, I. A., Venkataraman, S., Lander, G., Natarajan, P., Johnson, J. E., Brooks, C. I., \& Reddy, V. S. (2009). VIPERdb2: An enhanced and web API enabled relational database for structural virology. Nucleic Acids Research. https://doi.org/10.1093/nar/gkn840 
Chen, Y., \& Hu, X. (2013). High-throughput detection of banana bunchy top virus in banana plants and aphids using real-time TaqMan® PCR. Journal of Virological Methods. https://doi.org/10.1016/j.jviromet.2013.06.013

Chiaki, Y., Nasir, N., Herwina, H., Jumjunidang, Sonoda, A., Fukumoto, T., Nakamura, M., \& Iwai, H. (2015). Genetic structure and diversity of the Banana bunchy top virus population on Sumatra Island, Indonesia. European Journal of Plant Pathology. https://doi.org/10.1007/s10658-015-0669-9

Dale, J. L. (1987). Banana bunchy top: An economically important tropical plant virus disease. Advances in Virus Research. https://doi.org/10.1016/S0065-3527(08)60321-8

Das, R., \& Baker, D. (2008). Macromolecular Modeling with Rosetta. Annual Review of Biochemistry. https://doi.org/10.1146/annurev.biochem.77.062906.171838

Eisenberg, D., \& Hill, C. P. (1989). Protein crystallography: more surprises ahead. Trends in Biochemical Sciences. https://doi.org/10.1016/0968-0004(89)90059-5

Elayabalan, S., Subramaniam, S., \& Selvarajan, R. (2015). Banana bunchy top disease (BBTD) symptom expression in banana and strategies for transgenic resistance: A review. In Emirates Journal of Food and Agriculture. https://doi.org/10.9755/ejfa.v27i1.19197

FAO. 2019. Banana Statistical Compendium 2018. Rome. (n.d.).

Fu, H.-C., Hu, J.-M., Hung, T.-H., Su, H.-J., \& Yeh, H.-H. (2009). Unusual Events Involved in Banana bunchy top virus Strain Evolution. Phytopathology, 99(7), 812-822. https://doi.org/10.1094/PHYTO-99-7-0812

Godzik, A., Kolinski, A., \& Skolnick, J. (1992). Topology fingerprint approach to the inverse protein folding problem. Journal of Molecular Biology. https://doi.org/10.1016/00222836(92)90693-E

Harding, R. M., Burns, T. M., \& Dale, J. L. (1991). Virus-like particles associated with banana bunchy top disease contain small single-stranded DNA. Journal of General Virology. https://doi.org/10.1099/0022-1317-72-2-225

He, F. (2011). Laemmli-SDS-PAGE. BIO-PROTOCOL. https://doi.org/10.21769/bioprotoc.80

Ho, P. T., Montiel-Garcia, D. J., Wong, J. J., Carrillo-Tripp, M., Brooks, C. L., Johnson, J. E., \& Reddy, V. S. (2018). VIPERdb: A Tool for Virus Research. Annual Review of Virology. https://doi.org/10.1146/annurev-virology-092917-043405

Hooks, C. R. R., Fukuda, S., Perez, E. A., Manandhar, R., Wang, K.-H., Wright, M. G., \& Almeida, R. P. P. (2009). Aphid Transmission of Banana Bunchy Top Virus to Bananas 
After Treatment With a Bananacide. Journal of Economic Entomology. https://doi.org/10.1603/029.102.0205

Horton, N., \& Lewis, M. (1992). Calculation of the free energy of association for protein complexes. Protein Science. https://doi.org/10.1002/pro.5560010117

INIBAP. (2002). Networking Banana and Plantain: INIBAP Annual Report 2001. In Report. Ishida, T., \& Kinoshita, K. (2007). PrDOS: Prediction of disordered protein regions from amino acid sequence. Nucleic Acids Research. https://doi.org/10.1093/nar/gkm363 Jeschke, G. (2018). MMM: A toolbox for integrative structure modeling. Protein Science. https://doi.org/10.1002/pro.3269

Källberg, M., Margaryan, G., Wang, S., Ma, J., \& Xu, J. (2014). Raptorx server: A resource for template-based protein structure modeling. Methods in Molecular Biology. https://doi.org/10.1007/978-1-4939-0366-5_2

Källberg, M., Wang, H., Wang, S., Peng, J., Wang, Z., Lu, H., \& Xu, J. (2012). Templatebased protein structure modeling using the RaptorX web server. Nature Protocols. https://doi.org/10.1038/nprot.2012.085

Kelley, L. A., Mezulis, S., Yates, C. M., Wass, M. N., \& Sternberg, M. J. E. (2015). The Phyre 2 web portal for protein modeling, prediction and analysis. Nature Protocols. https://doi.org/10.1038/nprot.2015.053

Kelley, L. A., \& Sternberg, M. J. E. (2009). Protein structure prediction on the web: A case study using the phyre server. Nature Protocols. https://doi.org/10.1038/nprot.2009.2

Kim, D. E., Chivian, D., \& Baker, D. (2004). Protein structure prediction and analysis using the Robetta server. Nucleic Acids Research. https://doi.org/10.1093/nar/gkh468

King, A. M. Q., Adams, M. J., Carstens, E. B., \& Lefkowitz, E. J. (2012). Family Nanoviridae. In Virus Taxonomy.

Kumar, P. L., Hanna, R., Alabi, O. J., Soko, M. M., Oben, T. T., Vangu, G. H. P., \& Naidu, R. A. (2011). Banana bunchy top virus in sub-Saharan Africa: Investigations on virus distribution and diversity. Virus Research. https://doi.org/10.1016/j.virusres.2011.04.021

Laskowski, R. A., MacArthur, M. W., \& Thornton, J. M. (2012). PROCHECK : validation of protein-structure coordinates . https://doi.org/10.1107/97809553602060000882

Malathi, V. G., \& Renuka Devi, P. (2019). ssDNA viruses: key players in global virome. VirusDisease, 30(1), 3-12. https://doi.org/10.1007/s13337-019-00519-4

Mandal, B. (2010). Advances in small isometric multicomponent ssDNA viruses infecting plants. In Indian Journal of Virology. https://doi.org/10.1007/s13337-010-0010-3

Mansoor, S., Qazi, J., Amin, I., Khatri, A., Khan, I. A., Raza, S., Zafar, Y., \& Briddon, R. W. 
(2005). A PCR-based method, with internal control, for the detection of Banana bunchy top virus in Banana. Molecular Biotechnology. https://doi.org/10.1385/MB:30:2:167

Ovchinnikov, S., Park, H., Kim, D. E., DiMaio, F., \& Baker, D. (2018). Protein structure prediction using Rosetta in CASP12. Proteins: Structure, Function and Bioinformatics. https://doi.org/10.1002/prot.25390

Paz, I., Kligun, E., Bengad, B., \& Mandel-Gutfreund, Y. (2016). BindUP: a web server for non-homology-based prediction of DNA and RNA binding proteins. Nucleic Acids Research. https://doi.org/10.1093/nar/gkw454

Pontius, J., Richelle, J., \& Wodak, S. J. (1996). Deviations from Standard Atomic Volumes as a Quality Measure for Protein Crystal Structures. Journal of Molecular Biology, 264(1), 121-136. https://doi.org/10.1006/jmbi.1996.0628

Prasad, B. V. V., \& Schmid, M. F. (2012). Principles of Virus Structural Organization (pp. 17-47). https://doi.org/10.1007/978-1-4614-0980-9_3

Qazi, J. (2016). Banana bunchy top virus and the bunchy top disease. In Journal of General Plant Pathology. https://doi.org/10.1007/s10327-015-0642-7

Sangita, V., Lokesh, G. L., Satheshkumar, P. S., Vijay, C. S., Saravanan, V., Savithri, H. S., $\&$ Murthy, M. R. N. (2004). T=1 capsid structures of Sesbania mosaic virus coat protein mutants: Determinants of $\mathrm{T}=3$ and $\mathrm{T}=1$ capsid assembly. Journal of Molecular Biology. https://doi.org/10.1016/j.jmb.2004.07.003

Satheshkumar, P. S., Lokesh, G. L., Sangita, V., Saravanan, V., Vijay, C. S., Murthy, M. R. N., \& Savithri, H. S. (2004). Role of metal ion-mediated interactions in the assembly and stability of Sesbania mosaic virus $\mathrm{T}=3$ and $\mathrm{T}=1$ capsids. Journal of Molecular Biology. https://doi.org/10.1016/j.jmb.2004.07.022

Schrödinger. (2018). Maestro | Schrödinger. In Schrödinger Release 2018-1.

Selvarajan, R., \& Balasubramanian, V. (2013). Natural occurrence of banana bunchy top virus in ensete superbum in India. In Indian Journal of Virology. https://doi.org/10.1007/s13337-012-0123-y

Selvarajan, R., \& Balasubramanian, V. (2014). Host-virus interactions in banana-infecting viruses. In Plant Virus-Host Interaction: Molecular Approaches and Viral Evolution. https://doi.org/10.1016/B978-0-12-411584-2.00003-2

Selvarajan, R., Balasubramanian, V., Kavitha, K., Kavitha, K., Sathiamoorthy, S., \& Ahlawat, Y. (2008). Detection of Banana bunchy top virus and Banana streak Mysore virus by PCR: Impact of storing virus infected banana samples. Indian Journal of Virology, 19(2), 155-159. 
Selvarajan, R., Mary Sheeba, M., Balasubramanian, V., Rajmohan, R., Dhevi, N. L., \& Sasireka, T. (2010). Molecular Characterization of Geographically Different Banana bunchy top virus Isolates in India. Indian Journal of Virology, 21(2), 110-116. https://doi.org/10.1007/s13337-010-0020-1

Shekhawat, U. K. S., Ganapathi, T. R., \& Hadapad, A. B. (2012). Transgenic banana plants expressing small interfering RNAs targeted against viral replication initiation gene display high-level resistance to banana bunchy top virus infection. Journal of General Virology. https://doi.org/10.1099/vir.0.041871-0

Stainton, D., Martin, D. P., Muhire, B. M., Lolohea, S., Halafihi, M., Lepoint, P., Blomme, G., Crew, K. S., Sharman, M., Kraberger, S., Dayaram, A., Walters, M., Collings, D. A., Mabvakure, B., Lemey, P., Harkins, G. W., Thomas, J. E., \& Varsani, A. (2015). The global distribution of Banana bunchy top virus reveals little evidence for frequent recent, human-mediated long distance dispersal events . Virus Evolution. https://doi.org/10.1093/ve/vev009

Venkataraman, S., Reddy, S. P., Loo, J., Idamakanti, N., Hallenbeck, P. L., \& Reddy, V. S. (2008). Crystallization and preliminary X-ray diffraction studies of Seneca Valley Virus-001, a new member of the Picornaviridae family. Acta Crystallographica Section F: Structural Biology and Crystallization Communications. https://doi.org/10.1107/S1744309108006921

Venkataraman, S., \& Selvarajan, R. (2019). Recent advances in understanding the replication initiator protein of the ssDNA plant viruses of the family Nanoviridae. VirusDisease, 30(1), 22-31. https://doi.org/10.1007/s13337-019-00514-9

Vetten, H. J. (2008). Nanoviruses. In Encyclopedia of Virology. https://doi.org/10.1016/B978-012374410-4.00644-0

Vishnoi, R., Raj, S. K., \& Prasad, V. (2009). Molecular characterization of an Indian isolate of Banana bunchy top virus based on six genomic DNA components. Virus Genes, 38(2), 334-344. https://doi.org/10.1007/s11262-009-0331-8

Watanabe, S., Borthakur, D., \& Bressan, A. (2016). Localization of Banana bunchy top virus and cellular compartments in gut and salivary gland tissues of the aphid vector Pentalonia nigronervosa. Insect Science. https://doi.org/10.1111/1744-7917.12211

Wei, J., Liu, H., Liu, F., Zhu, M., Zhou, X., \& Xing, D. (2014). Miniaturized Paper-Based Gene Sensor for Rapid and Sensitive Identification of Contagious Plant Virus. ACS Applied Materials \& Interfaces, 6(24), 22577-22584. https://doi.org/10.1021/am506695g 
Wickramaarachchi, W. A. R. T., Shankarappa, K. S., Rangaswamy, K. T., Maruthi, M. N., Rajapakse, R. G. A. S., \& Ghosh, S. (2016). Molecular characterization of banana bunchy top virus isolate from Sri Lanka and its genetic relationship with other isolates. VirusDisease. https://doi.org/10.1007/s13337-016-0311-2

$\mathrm{Xu}, \mathrm{D}$., \& Zhang, Y. (2012). Ab initio protein structure assembly using continuous structure fragments and optimized knowledge-based force field. Proteins: Structure, Function and Bioinformatics, 80(7), 1715-1735. https://doi.org/10.1002/prot.24065

Xu, D., \& Zhang, Y. (2013). Toward optimal fragment generations for ab initio protein structure assembly. Proteins: Structure, Function and Bioinformatics, 81(2), 229-239. https://doi.org/10.1002/prot.24179

Yang, J., \& Zhang, Y. (2015). I-TASSER server: New development for protein structure and function predictions. Nucleic Acids Research. https://doi.org/10.1093/nar/gkv342

Yu, N. T., Feng, T. C., Zhang, Y. L., Wang, J. H., \& Liu, Z. X. (2011). Bioinformatic analysis of BBTV satellite DNA in hainan. Virologica Sinica. https://doi.org/10.1007/s12250-011-3196-7

Zhuang, J., Coates, C. J., Mao, Q., Wu, Z., \& Xie, L. (2016). The antagonistic effect of Banana bunchy top virus multifunctional protein B4 against Fusarium oxysporum. Molecular Plant Pathology, 17(5), 669-679. https://doi.org/10.1111/mpp.12319 
Tables:

Table 1: Comparison of the QMean scores of the models predicted by various servers and softwares. Default parameters were chosen for running the prediction/modelling and QMean scores were assessed using the site https://swissmodel.expasy.org/qmean/ (Benkert et al., 2009)

\begin{tabular}{|l|l|l|l|}
\hline S.No. & Software & Method & QMean4 \\
\hline 1 & iTasser & Ab initio & -13.03 \\
\hline 2 & Rosetta & Ab initio & -2.21 \\
\hline 3 & Swissmodel & Modelling & -3.57 \\
\hline 4 & hhPred & Modelling & -5.21 \\
\hline 4 & Schrodinger & Modelling & -7.62 \\
\hline 5 & Raptor & Modelling & -8.20 \\
\hline 6 & Phyr & Modelling & -15.02 \\
\hline 7 & MMM & Modelling & -4.53 \\
\hline
\end{tabular}


Table 2: The nucleic acid binding capacity of the amino terminal 26 residues as predicted by the BindUP server (Paz et al., 2016). POS: Index of amino acid residue, RES: Amino acid residue, S_LBL \& S_PRB: SVM prediction of binding label \& probability, K_LBL \& K_PRB: KLR prediction of binding, label \& probability, P_LBL \& P_PRB: PLR prediction of binding label \& probability, MAJ_CON: Majority consensus, STR_CON: Strict consensus, Labels 0/1 stand for non-binding/binding, respectively, Label NA stands for "label cannot be assigned".

\begin{tabular}{|l|l|l|l|l|l|l|l|l|l|}
\hline POS & RES & S_LBL & S_PRB & K_LBL & K_PRB & P_LBL & P_PRB & MAJ_CON & STR_CON \\
\hline 3 & R & 1 & 0.6481 & 1 & 0.6208 & 1 & 0.7480 & 1 & 1 \\
\hline 4 & Y & 1 & 0.6295 & 1 & 0.7573 & 1 & 0.7165 & 1 & 1 \\
\hline 5 & P & 1 & 0.6589 & 0 & 0.6004 & 1 & 0.5896 & 1 & NA \\
\hline 6 & K & 1 & 0.8477 & 1 & 0.8406 & 1 & 0.8695 & 1 & 1 \\
\hline 7 & K & 1 & 0.9378 & 1 & 0.9687 & 1 & 0.8411 & 1 & 1 \\
\hline 8 & S & 1 & 0.8557 & 1 & 0.6821 & 1 & 0.5779 & 1 & 1 \\
\hline 9 & I & 1 & 0.8306 & 1 & 0.9072 & 1 & 0.6931 & 1 & 1 \\
\hline 10 & K & 1 & 0.9576 & 1 & 0.9821 & 1 & 0.8328 & 1 & 1 \\
\hline 11 & K & 1 & 0.8083 & 1 & 0.8845 & 1 & 0.7831 & 1 & 1 \\
\hline 12 & R & 1 & 0.7560 & 1 & 0.7920 & 1 & 0.7163 & 1 & 1 \\
\hline 13 & R & 1 & 0.8760 & 1 & 0.9033 & 1 & 0.7962 & 1 & 1 \\
\hline 14 & V & 1 & 0.7354 & 1 & 0.7259 & 1 & 0.5227 & 1 & 1 \\
\hline 15 & G & 1 & 0.7321 & 1 & 0.6603 & 1 & 0.5968 & 1 & 1 \\
\hline 16 & R & 1 & 0.9340 & 1 & 0.9737 & 1 & 0.8899 & 1 & 1 \\
\hline 17 & R & 1 & 0.9484 & 1 & 0.9439 & 1 & 0.7992 & 1 & 1 \\
\hline 18 & K & 1 & 0.7806 & 1 & 0.6878 & 1 & 0.8730 & 1 & 1 \\
\hline 19 & Y & 1 & 0.8928 & 1 & 0.9688 & 1 & 0.8482 & 1 & 1 \\
\hline 20 & G & 1 & 0.6659 & 1 & 0.5998 & 1 & 0.7547 & 1 & 1 \\
\hline 21 & S & 1 & 0.8290 & 1 & 0.8448 & 1 & 0.8415 & 1 & 1 \\
\hline 22 & K & 1 & 0.7437 & 1 & 0.7864 & 1 & 0.7730 & 1 & 1 \\
\hline 23 & A & 1 & 0.7772 & 1 & 0.6564 & 1 & 0.6591 & 1 & 1 \\
\hline 24 & A & 1 & 0.6096 & 1 & 0.5350 & 1 & 0.5889 & 1 & 1 \\
\hline 25 & T & 1 & 0.6709 & 1 & 0.5969 & 1 & 0.5342 & 1 & 1 \\
\hline 26 & S & 1 & 0.6940 & 1 & 0.6322 & 1 & 0.6782 & 1 & 1 \\
\hline & & & & & & & & \\
\hline
\end{tabular}


Table 3: Contacts at the fivefold interface of the capsid as evaluated using the VIPERdb server (Ho et al., 2018). A stands for acidic, B for basic, $\mathrm{H}$ for hydrophobic and $\mathrm{P}$ for polar.

\begin{tabular}{|l|l|l|}
\hline Interface & A1-A7 & A1-A2 \\
\hline H-H & 0 & 5 \\
\hline H-P & 0 & 3 \\
\hline H-A & 0 & 2 \\
\hline H-B & 0 & 4 \\
\hline P-H & 1 & 4 \\
\hline P-P & 0 & 7 \\
\hline P-A & 1 & 0 \\
\hline P-B & 0 & 3 \\
\hline A-H & 0 & 1 \\
\hline A-P & 0 & 1 \\
\hline A-A & 0 & 1 \\
\hline A-B & 0 & 2 \\
\hline B-H & 0 & 1 \\
\hline B-P & 0 & 1 \\
\hline B-A & 0 & 2 \\
\hline B-B & 0 & 1 \\
\hline
\end{tabular}


bioRxiv preprint doi: https://doi.org/10.1101/2020.02 12.945212; this version posted February 13, 2020. The copyright holder for this preprint (which was not certified by peer review) is the author/funder. All rights reserved. No reuse allowed without permission.

Figures:

Figure 1: Bunchy top disease of banana caused by BBTV. a) Banana plant showing stunted bunchy appearance

due

to

BBTV

infection

(https://www.flickr.com/photos/scotnelson/42839451145). b) Infected leaf showing dark green dash pattern due to BBTV infection (https://www.flickr.com/photos/scotnelson/28824232288).
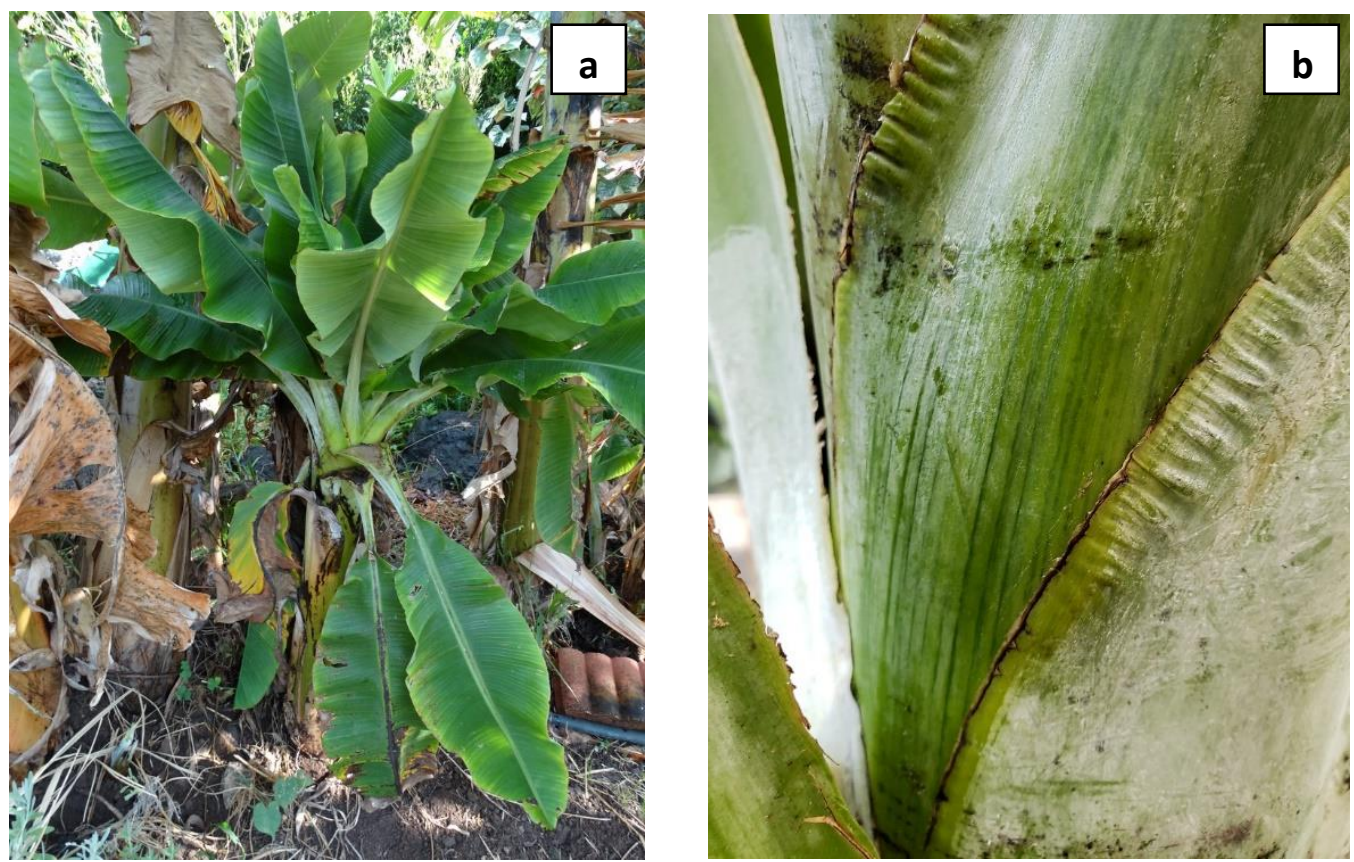
Figure 2: Cloning of CP gene in pET28a vector. a) The amplified CP gene of 513bp following PCR with DNA extracted from BBTV infected leaves. Lane 1 DNA marker, Lanes 2, 4 and 5 show the amplified CP band corresponding to 513bp. b) Confirmation of insert following cloning into pET28a. Lane $1 \mathrm{CP}$ fragment released after restriction digestion with XhoI and NhoI, lane 2 Full length plasmid, lane 3 is the marker DNA.

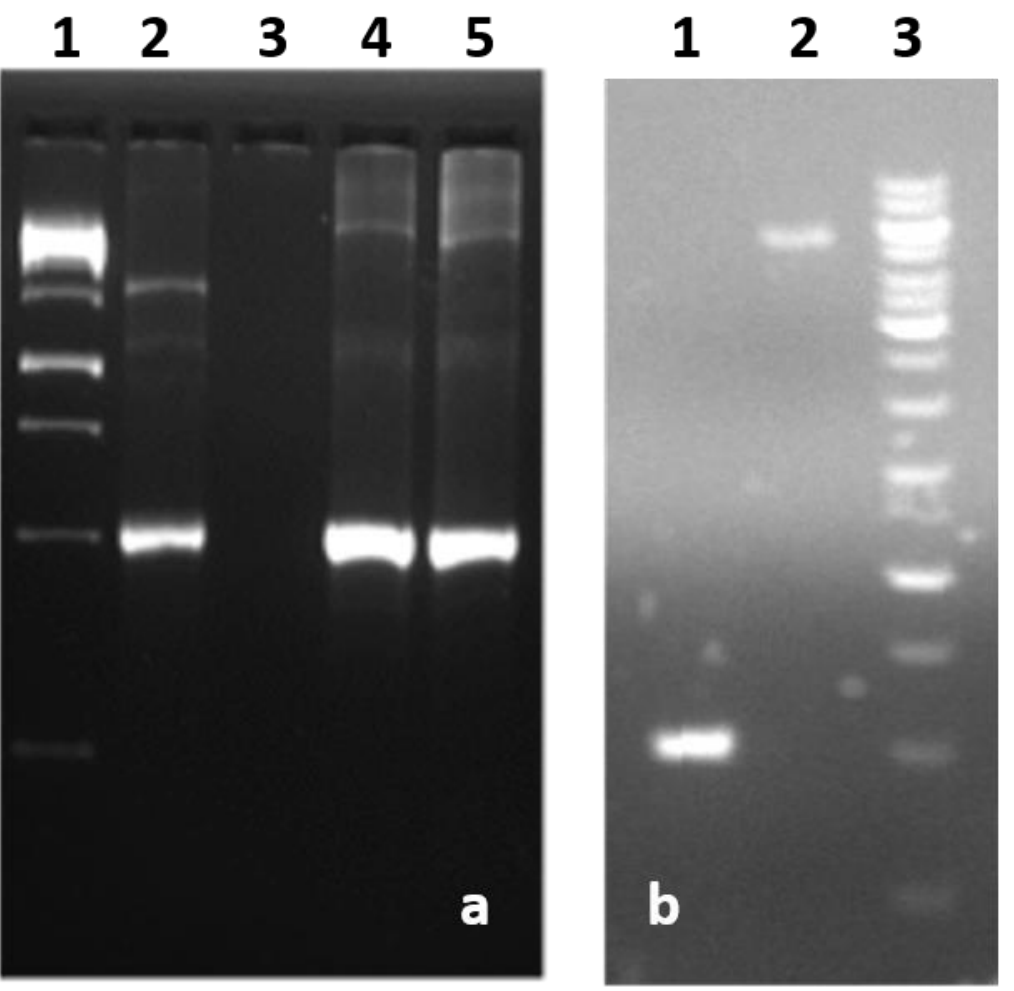


Figure 3: Expression and purification of CP gene in BL21 (DE3). a) Protein expression was induced by $1 \mathrm{M}$ IPTG kept at $37^{\circ} \mathrm{C}$ for 3 hours following induction. Lanes 1 shows uninduced sample, Lane 2 and 3 show the insoluble and soluble component following cell lysis. b) Lane 1 Protein marker, Lanes 2, 3, 4 and 5 wash through of Ni-NTA binding,Lane 6 eluted protein.

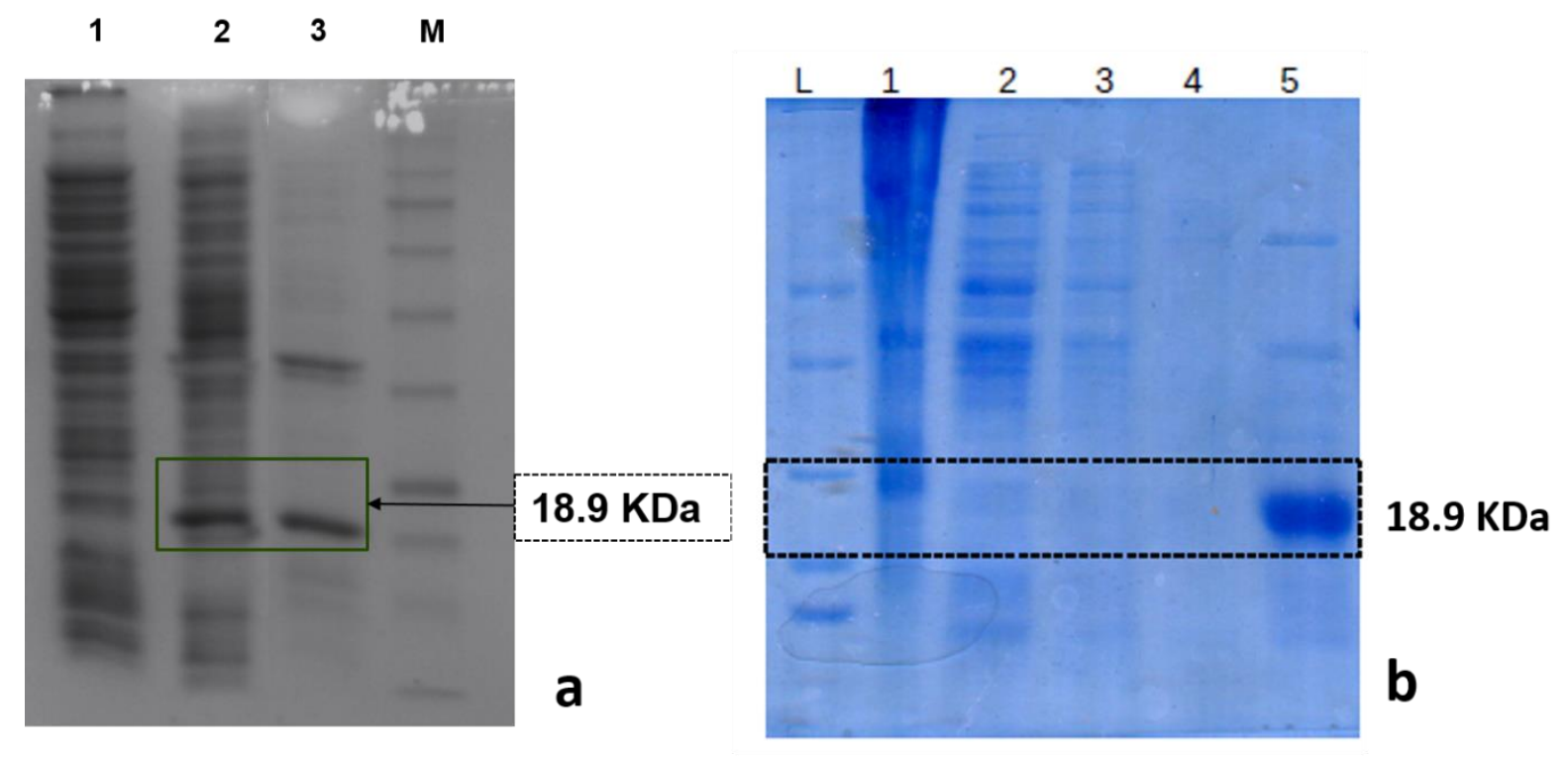


Figure 4: Protein homogeneity and assembly study a) DLS of purified CP showing the preponderance of pentamers. b) Sucrose density gradient profile showing the absence of VLPs in the protein preparation.
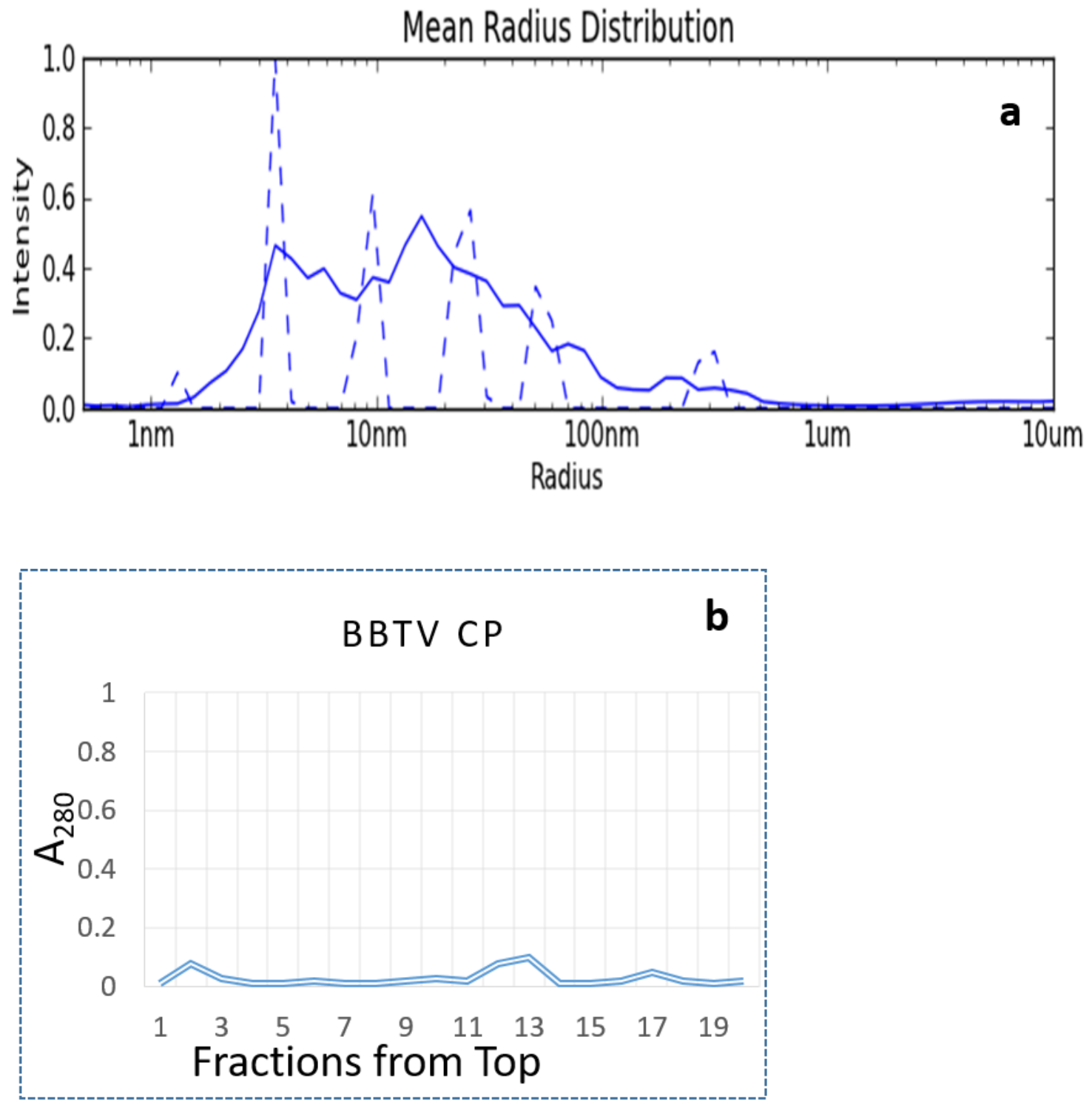
Figure 5: a) Predicted model quality as determined by PROCHECK using the SAVES server (Laskowski et al., 2012; Pontius et al., 1996). More than $82 \%$ of the residues are seen in the most favorable region. b) Disorder prediction by PrDOS server that shows a highly disordered amino terminal region (Ishida \& Kinoshita, 2007).
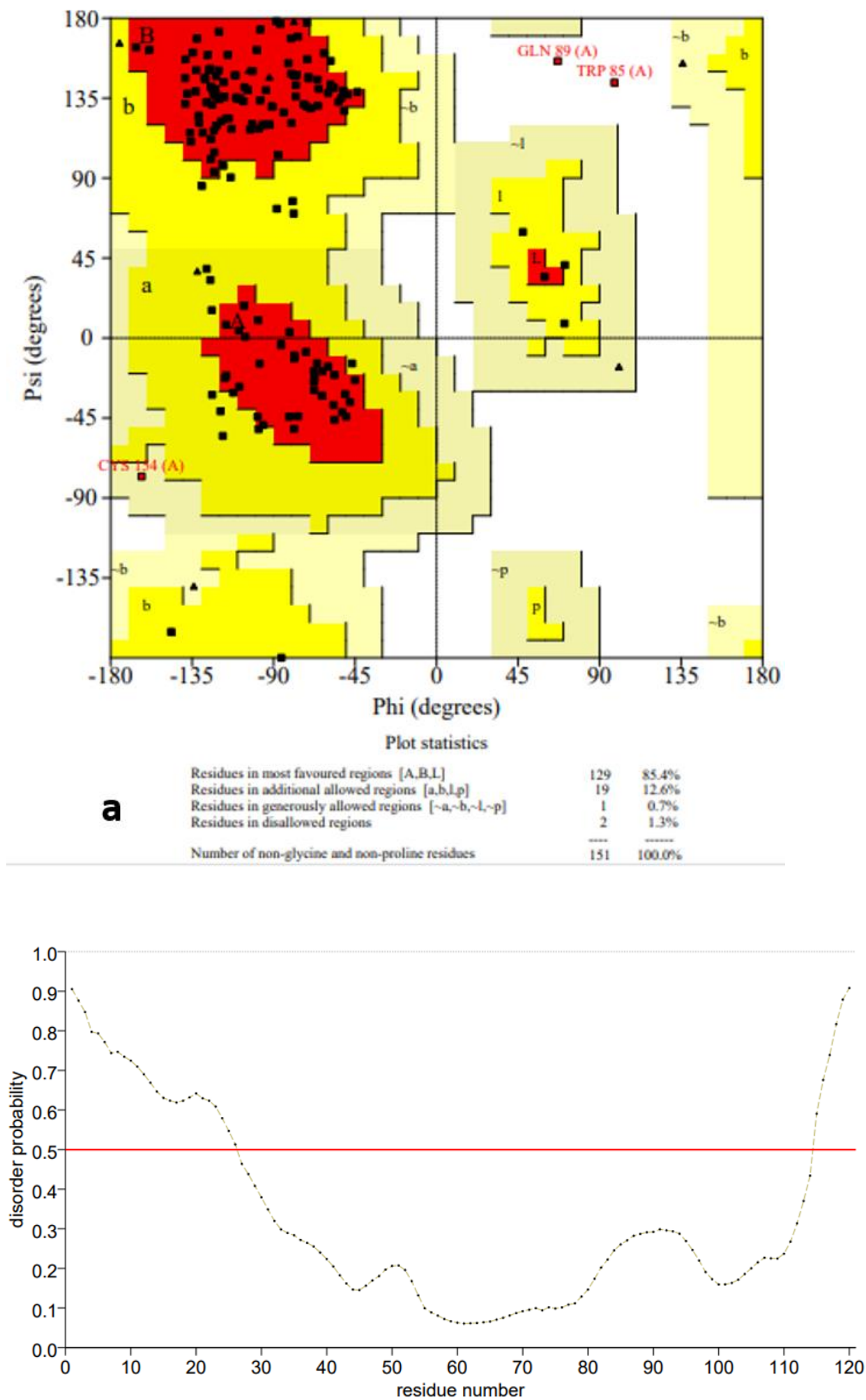

b 
Figure 6: a) Surface representation of the CP showing the highly basic amino terminal region in blue (acidic red and neutral white) that is implicated in binding to the nucleic acid. b) Cartoon representation showing the $\beta$-sandwich fold of the CP. The $\beta$ strands are coloured in blue, $\alpha$ helices in green and loops are in yellow.
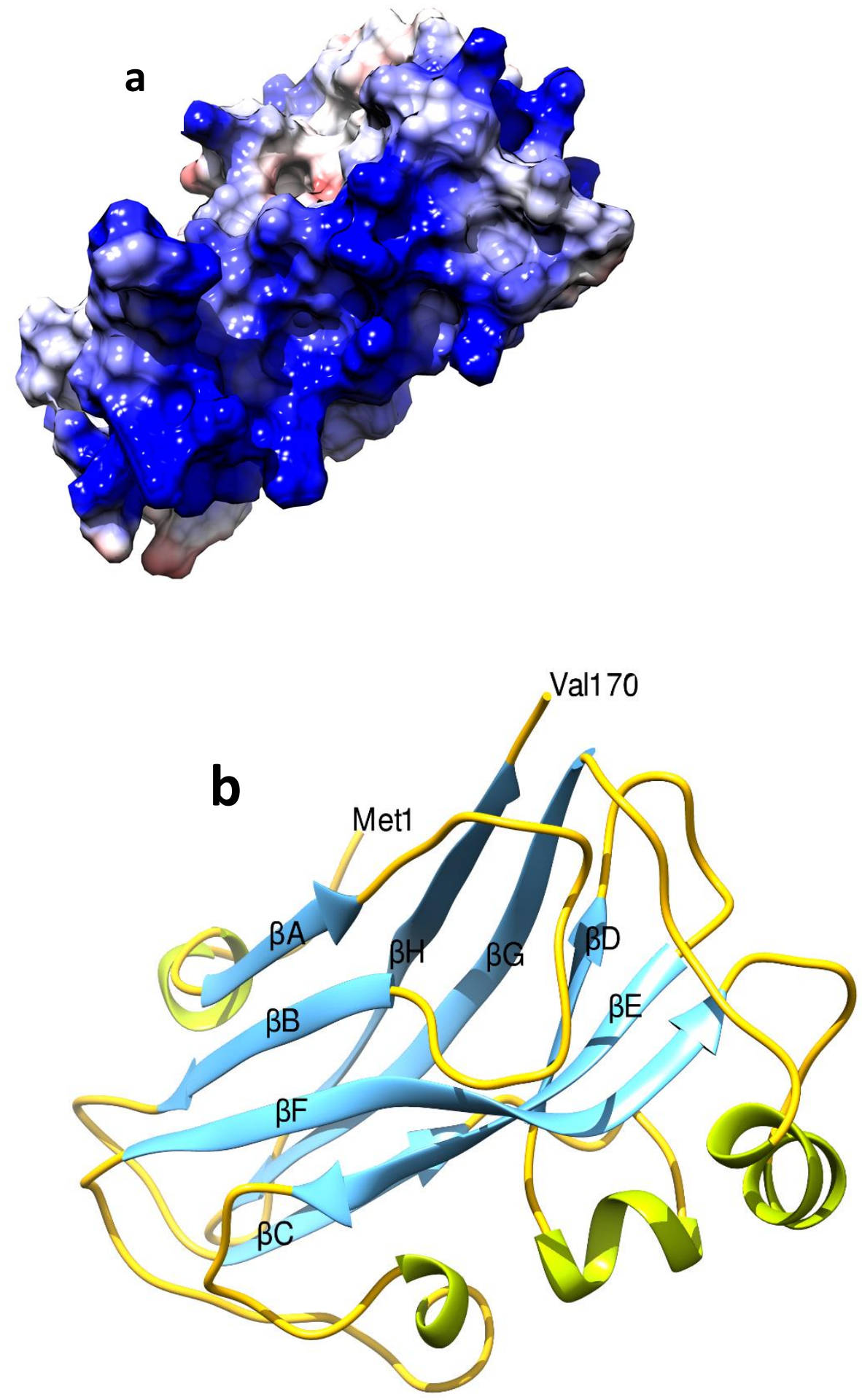
bioRxiv preprint doi: https://doi.org/10.1101/2020.02 12 945212; this version posted February 13, 2020. The copyright holder for this preprint (which was not certified by peer review) is the author/funder. All rights reserved. No reuse allowed without permission.

Figure7: a) Surface representation of the capsid looking down the five fold axis of the icosahedron. b) The aphid binding motif EAG shown as red sphered located at the highly accessible loop between $\beta \mathrm{F}$ and $\beta \mathrm{G}$ at the pentameric axes.
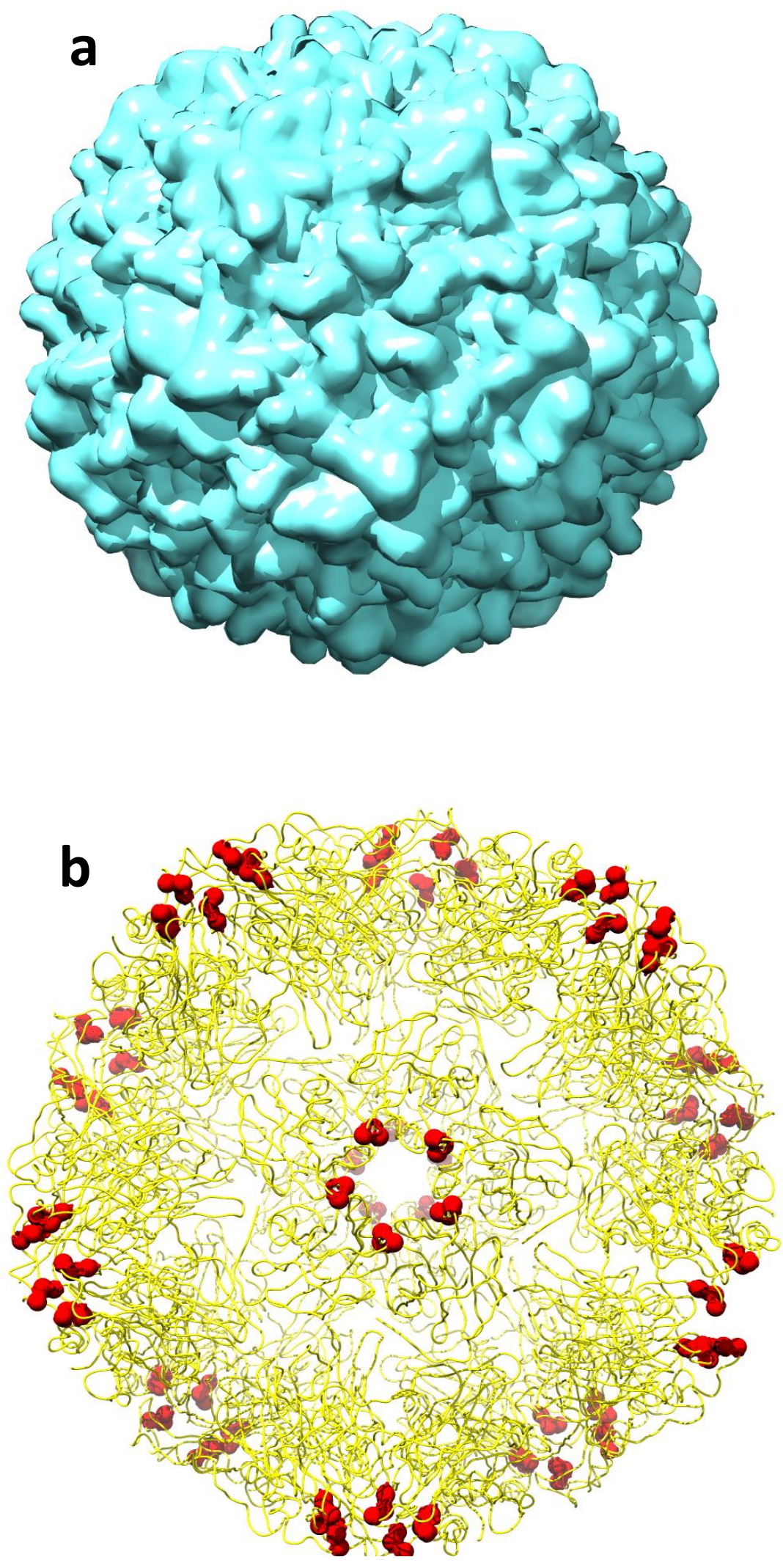